\title{
DNA methylation change in neurotrophic genes with aging and delirium evidenced from
}

\section{three independent cohorts}

Taku Saito $^{\text {a, b}}$, Patricia R. Braun ${ }^{\text {, }}$, Sophia Daniel ${ }^{\text {a }}$, Sydney S. Jellison ${ }^{\text {a }}$, Mandy Hellman ${ }^{\text {a }}$, Eri

Shinozaki ${ }^{d}$, Sangil Lee ${ }^{e}$, Hyunkeun R. Cho $^{f}$, Aihide Yoshino ${ }^{b}$, Hiroyuki Toda ${ }^{b}$, Gen Shinozaki ${ }^{a}$ $\mathrm{g}, \mathrm{h}, \mathrm{i}$, *

${ }^{a}$ Department of Psychiatry, ${ }^{d}$ Department of Internal Medicine, ${ }^{e}$ Department of Emergency

Medicine, ${ }^{g}$ Department of Neurosurgery, Carver College of Medicine, ${ }^{f}$ Department of

Biostatistics, College of Public Health, ${ }^{\mathrm{h}}$ lowa Neuroscience Institute, ${ }^{\mathrm{i}}$ Interdisciplinary Graduate

Program in Neuroscience,

University of lowa, lowa City, lowa, USA

${ }^{\mathrm{b}}$ Department of Psychiatry, School of Medicine, National Defense Medical College, Tokorozawa, Saitama, Japan

${ }^{\mathrm{c}}$ Department of Psychiatry and Behavioral Science, Johns Hopkins University School of Medicine, Baltimore, Maryland, USA.

*Corresponding author: Gen Shinozaki, M.D.

Department of Psychiatry, Carver College of Medicine, University of lowa

25 S. Grand Ave, Medical Laboratories, B002, lowa City, IA 52242, USA.

Phone: +1-319-384-4932, Fax: +1-319-353-3003

Email: gen-shinozaki@uiowa.edu 


\section{Abstract}

INTRODUCTION: We previously reported the association between DNA methylation (DNAm) of pro-inflammatory cytokine genes and aging. Neurotrophic factors are also known to be associated with aging and neurocognitive disorders. Thus, we hypothesized that DNAm of neurotrophic genes change with aging, especially in delirium patients.

METHODS: DNAm were analyzed using HumanMethylationEPIC BeadChip Kit in 3 independent cohorts; blood from 383 Grady Trauma Project subjects, brain from 21 neurosurgery patients, and blood from 87 inpatients with and without delirium.

RESULTS: Both blood and brain samples showed that most of the DNAm of neurotrophic genes were positively correlated with aging. Furthermore, DNAm of neurotrophic genes were positively correlated with aging in delirium cases than in non-delirium controls.

DISCUSSION: These findings support our hypothesis that the neurotrophic genes may be epigenetically modulated with aging, and this process may be contributing to the pathophysiology of delirium.

\section{Keywords}

Delirium; Aging; Genome-wide DNA methylation; Neurotrophic factor; BDNF; GDNF 


\section{INTRODUCTION}

Although delirium is common among elderly patients [1], it is underdiagnosed and undertreated [2]. Various screening methods have been developed to characterize the epidemiology and risk factors of delirium (e.g., the Confusion Assessment Method (CAM) (Inouye et al., 1990) and Confusion Assessment Method for Intensive Care Unit (CAM-ICU) [3, 4]). Although they have excellent sensitivity and specificity in research settings, they are found to have suboptimal sensitivity (38-47\%) in the context of "real world" intensive care units [5, 6]. Thus, among the elderly at high risk for delirium, biomarkers of delirium would aid in the prediction and treatment of delirium.

Previously we reported the association of DNA methylation (DNAm) changes in proinflammatory cytokine genes with aging, indicating its possible role in the pathophysiology of delirium [7]. This emphasized past findings of the importance of neuroinflammation in the development of delirium with the additional link of DNAm changes. However, the etiology of delirium is complex with many facets leading up to its manifestation, and it is important to look at additional factors involved. Given the evidence of neurotrophic factors being associated with age-related behavior, it is possible that DNAm of these genes may be differentially regulated in the context of aging with delirium $[8,9]$.

Neurotrophic factors are signaling molecules that contribute to neural plasticity, learning, and memory [10]. Decreased serum levels of the brain-derived neurotrophic factor (BDNF) were associated with cognitive impairment in elderly people [11]. Serum levels of the glial cell linederived neurotrophic factor (GDNF) as well as BDNF were decreased in subjects with mild cognitive impairment and Alzheimer's disease [12]. A Neuronal Per-Arnt-Sim domain protein 4 (NPAS4) knockdown mouse model showed increased cell death in cortical neurons [13]. This invivo investigation also revealed an increased lesion size and greater neurodegeneration after a photochemically-induced stroke [13]. The nuclear receptor subfamily 4A2 (NR4A2) critically 
regulates Alzheimer's disease (AD)-related pathophysiology [14]. A NR4A2 knockdown mouse model exacerbates AD symptoms/pathology of neuroinflammation/degeneration, and plaque accumulation. Administration of the FDA-approved NR4A2 modulating drug significantly reduced cognitive impairments and plaque numbers [14].

Aging alters gene expression in the brain drastically $[15,16]$ and such changes are regulated by a variety of epigenetic modifications including DNAm [17], histone modifications [18], and micro RNA-mediated transcriptional control $[19,20]$. Indeed, DNAm patterns have been shown to change dynamically throughout the human lifespan [21], and epigenetic processes involved in aging have been studied in detail [22-26]. It has previously been shown that DNAm levels of $B D N F$ is significantly correlated with age in blood [27], but whether this is exacerbated or dysregulated in age-related disorders, such as delirium, needs to be studied. Our aim was to first expand upon this study and examine whether DNAm of additional neurotrophic genes are significantly correlated with aging in blood and brain tissues in non-delirium populations. Second, we wanted to compare to what degree the DNAm levels of the neurotrophic genes were correlated in delirium cases versus controls.

In this study, we analyzed samples from three cohorts to examine the degree of correlation between DNAm and age in neurotrophic genes. We hypothesized that DNAm in neurotrophic genes in both brain and blood would increase with aging, and that these associations would be more significant in delirium patients. 


\section{METHODS}

\section{Grady Trauma Project (GTP) Cohort Sample Processing}

Three hundred and eighty-three subjects (age average $=41.50$, age $\mathrm{SD}=12.93$, age range $=$ 18-77, female; $n=273$, race $=380$ African American, 2 Native American and 1 other) were analyzed from the Grady Trauma Project (GTP) cohort. Detailed information of this cohort has been previously described [7]. DNAm data was processed by using Illumina HumanMethylation450. Processing of the dataset has been described previously [28].

\section{Neurosurgery (NSG) Cohort Sample Processing}

Twenty-one subjects were analyzed from the neurosurgery (NSG) cohort. Details of this cohort are described in a previous study [29]. Resected brain tissue was collected from subjects with intractable epilepsy who underwent neurosurgery. Written informed consent was obtained from all of the participants. This study was approved by the University of lowa's Human Subjects Research Institutional Review Board. DNAm was assessed with the Infinium HumanMethylationEPIC BeadChip ${ }^{\text {TM }}$ Kit (Illumina, WG-317-1002). The R packages RnBeads and Minfi $[30,31]$ were used to process the raw data and perform quality control checks, data filtering, and normalization techniques [30-32].

\section{Epigenetics of Delirium (EOD) Cohort Subjects}

A separate ongoing study of delirium was performed at the University of lowa Hospitals and Clinics. Further characteristics of this cohort were detailed previously [7, 33, 34]. Ninety-two subjects participated between November 2017 and October 2018. Among them, eighty-seven subjects (age average $=70.2$ years, age $S D=10.2$, age range $=42-101$ years, male; $n=60$ ) were analyzed as described below. Written informed consent was obtained from all of the participants, and this study was approved by the University of lowa's Human Subjects Research Institutional Review Board. 


\section{Definition of Delirium Status}

Details of the EOD cohort inclusion/exclusion criteria have been previously described [33].

Briefly, participants were screened for delirium by hospital records, the Confusion Assessment Method for Intensive Care Unit (CAM-ICU) [3], the Delirium Rating Scale - Revised-98 (DRS-R98) [35], and the Delirium Observation Screening Scale (DOSS) [36]. A final decision of delirium phenotyping was conducted by trained psychiatrist (G.S.).

\section{EOD Sample Processing}

For the EOD cohort, whole blood samples were collected with EDTA tubes, and all samples were stored at $-80^{\circ} \mathrm{C}$. Genomic DNA was extracted with the MasterPure ${ }^{\mathrm{TM}}$ DNA Purification kit (Epicentre, MCD85201) and bisulfite-converted with the EZ DNA Methylation ${ }^{\mathrm{TM}} \mathrm{Kit}$ (Zymo Research, D5002).

\section{EOD Methylome Ananalysis}

The Infinium HumanMethylationEPIC BeadChip ${ }^{T M}$ Kit (Illumina, WG-317-1002) was used to process DNAm levels of 93 samples (two samples were from one subject). The R packages ChAMP [37] and minfi $[30,38]$ were used to process the raw data. Using the ChAMP package, one sample was filtered out because it had above $10 \%$ of sites with detection $p$-value greater than 0.01 , and $\mathrm{CpG}$ sites were filtered out as described below. This resulted in 92 samples and 701,196 probes. Additional outlier samples were found with the density and multidimensional scaling plots. This included five samples, two of which were the duplicate samples from the same individual. The remaining 87 samples (43 samples were cases) were reprocessed with the ChAMP package. CpG sites were filtered out if they 1) had a detection $p$-value greater than 0.01 (12,903 probes), 2) had less than three beads in at least $5 \%$ of samples per probe $(8,280$ probes), 3) were non-CpG probes (2,911 probes), 4) were SNP-related probes [39] $(94,425$ probes), 5) were cross-reactive probes [40] (11 probes), or 6) were located on the $X$ or $Y$ 
chromosome (16,356 probes). . Samples were normalized with beta mixture quantile dilation [41], and the Combat method was used to correct for batch effect $[42,43]$. The final dataset contained 731,032 sites.

\section{Statistical Analysis}

All statistical analyses were performed with $\mathrm{R}$ [44]. The correlation between age and DNAm levels of neurotrophic genes in each CpGs were tested by Pearson's correlation analysis. 


\section{RESULTS}

\section{DNA methylation and expression from GTP cohort blood samples}

We investigated the association between aging and DNAm levels at CpGs in seven neurotrophic genes; BDNF, GDNF, activity regulated cytoskeleton associated protein $(A R C)$, Fos Proto-Oncogene, AP-1 Transcription Factor Subunit (FOS), NPAS4, nuclear receptor subfamily $4 A 1$ (NR4A1) and NR4A2. To test this, we first used the GTP cohort that includes blood samples from 383 subjects. In the processed GTP methylome dataset, there are 226 CpGs annotated to be in the seven neurotrophic genes. Of these, DNAm of $16 \mathrm{CpGs}$ were significantly associated with aging genome-wide significance levels ( $p<5 \times E-8)$, including seven CpGs in BDNF and four CpGs in GDNF. The top hits were at a $\mathrm{CpG}$ in in GDNF $(\operatorname{cg} 02328239 ; p=1.54 \times E-20)$, and a CpG in BDNF (cg05733135; $p=4.49 \times E-15)$ (Table 1, Figure 1). Among top $53 \mathrm{CpGs}$ with $\mathrm{p}<2 \times \mathrm{E}-4$ (Bonferroni corrected for $226 \mathrm{CpGs}$, significant level $p<0.05 / 226), 49$ CpGs $(92.5 \%)$ were positively correlated with aging (Table 1). 109 CpGs were associated with aging at nominal significance $(p<0.05)$. Correlations between age and DNAm levels at $226 \mathrm{CpGs}$ were shown in Supplementary Table 1.

\section{NSG study samples, DNAm in brain}

We next tested whether these associations of DNAm in the GTP cohort were also present in brain tissue in our NSG cohort $(\mathrm{N}=21)$. We focused on top 4 genes based on the $16 \mathrm{CpGs}$ significantly associated with aging at genome-wide significant levels in the GTP cohort (BDNF, GDNF, NR4A2, and NPAS4). In BDNF, $18 \mathrm{CpGs}$ were positively correlated with aging at nominal significance $(p<0.05)$, whereas 4 CpGs were negatively correlated with aging at nominal significance (Table 2). Similarly, 15 CpGs were positively correlated with aging at nominal significance, whereas no CpGs were negatively correlated with aging at nominal significance in GDNF, $20 \mathrm{CpGs}$ were positively correlated with aging at nominal significance, 
whereas $3 \mathrm{CpGs}$ were negatively correlated with aging at nominal significance in $N R 4 A 2$, and 2 CpGs were positively correlated with aging at nominal significance, whereas no CpGs were negatively correlated with aging at nominal significance in NPAS4 (Table 2). Furthermore, the top hit $\mathrm{CpG}$ at $\mathrm{cg} 02328239$ in GDNF in the GTP study $(p=1.54 \times \mathrm{E}-20)$ was also positively correlated with aging at multiple testing significant level (Bonferroni corrected for 201 CpGs, significant level $p<0.05 / 201=2.49 \times E-4)$ in brain tissue in the NSG study (Table 2). In fact, among the nominal significant $(p<0.05)$ CpGs in brain tissue in the NSG study, 3 CpGs in BDNF, 3 CpGs in GDNF, 3 CpGs in NR4A2, and 2 CpGs in NPAS4 were also nominally significant in the GTP study (Table 1, 2). Correlations between age and DNAm levels at 201 CpGs were shown in Supplementary Table 2.

\section{Comparison of delirium cases vs non-delirium controls in EOD study samples}

We next expanded upon our previous analyses in population of delirium patients to determine if there were differences in the degrees of correlation for neurotrophic genes between DNAm and aging among delirium cases and controls. We evaluated the degree of correlation between age and DNAm levels at CpGs in BDNF (Table 3), GDNF, NR4A2, and NPAS4 (Supplementary Tables 3-5). Delirium cases showed 1 significant $\mathrm{CpG}$ after correction for multiple testing level $(p<0.05 / 192=7.35 \times E-4)$ in $B D N F$, whereas non-delirium controls showed no significant CpGs after correction for multiple testing level (Table 3). Furthermore, there were more nominal significant $(p<0.05)$ CpGs in delirium cases than in non-delirium controls with BDNF (5 in delirium cases vs. 3 in non-delirium controls), GDNF (5 vs. 2), and NR4A2 (3 vs. 0). Also, there were more positively correlated $\mathrm{CpGs}$ in delirium cases than in non-delirium controls with $B D N F$, GDNF, and NPAS4. 


\section{DISCUSSION}

In the present study, DNAm of the neurotrophic genes were positively associated with aging in both the blood and brain samples. Furthermore, these DNAm were more positively correlated with aging in delirious patients than controls. These results support our hypothesis that DNAm in neurotrophic genes in both brain and blood increases with aging, and such changes are more significant among delirium patients.

Data from the GTP cohort blood samples showed that the majority (96 among 109 CpGs; 88.1\%) of the nominally significant CpGs were positively correlated with aging. With the NSG cohort brain samples, we also found that the majority (55 among $62 \mathrm{CpGs;} 88.7 \%$ ) of the nominally significant $\mathrm{CpGs}$ were positively correlated with aging. Furthermore, the top hit $\mathrm{CpG}$ in the GTP study was also significantly positively correlated in the NSG study with brain samples. In total, 6 among the 16 significant CpGs after Bonferroni corrected genome-wide significance levels in the GTP cohort were also nominally significant in the NSG cohort. These results indicated that some neurotrophic $\mathrm{CpGs}$ show similar associations between aging and DNAm levels in brain and blood tissues.

In the EOD cohort more CpGs in neurotrophic genes were positively correlated with aging in delirium cases than in controls. This is consistent with our hypothesis that neurotrophic genes show greater DNAm changes with aging among elderly patients, indicating these genes may be dysregulated with altered expression levels compared to controls.

Studies of the relationship between circulating BDNF levels and delirium reveal mixed results. Higher plasma BDNF levels were associated with emergence of agitation in elderly patients after gastrointestinal surgery [45]. In patients with spine surgery, an intraoperative decline in plasma BDNF was greater in patients who developed delirium [46]. A study of ICU patients showed that serum level of $B D N F$ was significantly higher in delirium patients than in non- 
delirious controls [47]. No significant differences between delirium cases and controls were found in both a study of oncology inpatients [48], nor in acute medical inpatients [49].

There are limitations to this study. First, the NSG cohort was limited in sample size due to the infrequent occurrence of neurosurgical cases. Second, both blood and brain tissues consist of heterogeneous cellular populations. Third, a peripheral tissue, blood, had to be used to assess DNAm levels in the EOD cohort of delirium patients despite brain being the main organ of interest for delirium. Fourth, longitudinal studies are needed to distinguish whether the neurotrophic genes show more significantly correlated DNAm levels with aging prior to delirium onset.

To the best of our knowledge, this is the first study to analyze the degree of correlation between DNAm in neurotrophic genes and age in delirium patients. We found $16 \mathrm{CpGs}$ in BDNF, GDNF, NR4A2, NPAS4, NR4A1, and $A R C$ to be significantly correlated with aging in the large GTP cohort with blood samples, 6 of these CpGs were also nominally significant in the NSG cohort of brain samples. Within the delirium cohort itself, 8 more $\mathrm{CpGs}$ in the neurotrophic genes were associated with aging in cases than controls with the majority showing positive correlation. These findings provide initial evidence that the neurotrophic genes may be epigenetically modulated with aging, and in patients with delirium, this process may be dysregulated. 


\section{FUNDING}

This work was supported by research grants from National Science Foundation1664364; and the National Institute of Mental Health (K23 MH107654).

\section{DISCLOSURES}

Dr. Shinozaki G is co-founder of Predelix Medical LLC, and reports U.S. Provisional Patent Application No. 62/731599, titled "Epigenetic biomarker of delirium risk." The other authors report no financial interests or potential conflicts of interest. 


\section{REFERENCES}

[1] Inouye SK. Delirium in older persons. N Engl J Med. 2006;354:1157-65.

[2] Spronk PE, Riekerk B, Hofhuis J, Rommes JH. Occurrence of delirium is severely underestimated in the ICU during daily care. Intensive Care Med. 2009;35:1276-80.

[3] Ely EW, Inouye SK, Bernard GR, Gordon S, Francis J, May L, et al. Delirium in mechanically ventilated patients: validity and reliability of the confusion assessment method for the intensive care unit (CAM-ICU). JAMA. 2001;286:2703-10.

[4] Ely EW, Margolin R, Francis J, May L, Truman B, Dittus R, et al. Evaluation of delirium in critically ill patients: validation of the Confusion Assessment Method for the Intensive Care Unit (CAM-ICU). Crit Care Med. 2001;29:1370-9.

[5] van Eijk MM, van den Boogaard M, van Marum RJ, Benner P, Eikelenboom P, Honing ML, et al. Routine use of the confusion assessment method for the intensive care unit: a multicenter study. Am J Respir Crit Care Med. 2011;184:340-4.

[6] Nishimura K, Yokoyama K, Yamauchi N, Koizumi M, Harasawa N, Yasuda T, et al. Sensitivity and specificity of the Confusion Assessment Method for the Intensive Care Unit (CAM-ICU) and the Intensive Care Delirium Screening Checklist (ICDSC) for detecting postcardiac surgery delirium: A single-center study in Japan. Heart \& lung : the journal of critical care. $2016 ; 45: 15-20$.

[7] Shinozaki G, Braun PR, Hing BWQ, Ratanatharathorn A, Klisares MJ, Duncan GN, et al. Epigenetics of Delirium and Aging: Potential Role of DNA Methylation Change on Cytokine Genes in Glia and Blood Along With Aging. Front Aging Neurosci. 2018;10:311.

[8] Li G, Peskind ER, Millard SP, Chi P, Sokal I, Yu C-E, et al. Cerebrospinal fluid concentration of brain-derived neurotrophic factor and cognitive function in non-demented subjects. PLoS One. 2009;4:e5424. 
[9] Gunstad J, Benitez A, Smith J, Glickman E, Spitznagel MB, Alexander T, et al. Serum brainderived neurotrophic factor is associated with cognitive function in healthy older adults. J Geriatr Psychiatry Neurol. 2008;21:166-70.

[10] Ghitza UE, Zhai H, Wu P, Airavaara M, Shaham Y, Lu L. Role of BDNF and GDNF in drug reward and relapse: a review. Neurosci Biobehav Rev. 2010;35:157-71.

[11] Shimada H, Makizako H, Yoshida D, Tsutsumimoto K, Anan Y, Uemura K, et al. A large, cross-sectional observational study of serum BDNF, cognitive function, and mild cognitive impairment in the elderly. Front Aging Neurosci. 2014;6:69.

[12] Forlenza OV, Miranda AS, Guimar I, Talib LL, Diniz BS, Gattaz WF, et al. Decreased neurotrophic support is associated with cognitive decline in non-demented subjects. $\mathrm{J}$ Alzheimers Dis. 2015;46:423-9.

[13] Choy FC, Klarić TS, Leong WK, Koblar SA, Lewis MD. Reduction of the neuroprotective transcription factor Npas4 results in increased neuronal necrosis, inflammation and brain lesion size following ischaemia. J Cereb Blood Flow Metab. 2016;36:1449-63.

[14] Moon M, Jung ES, Jeon SG, Cha MY, Jang Y, Kim W, et al. Nurr1 (NR4A2) regulates Alzheimer' s disease - related pathogenesis and cognitive function in the 5XFAD mouse model. Aging cell. 2019;18:e12866.

[15] Berchtold NC, Cribbs DH, Coleman PD, Rogers J, Head E, Kim R, et al. Gene expression changes in the course of normal brain aging are sexually dimorphic. Proc Natl Acad Sci U S A. 2008;105:15605-10.

[16] Kang HJ, Kawasawa YI, Cheng F, Zhu Y, Xu X, Li M, et al. Spatio-temporal transcriptome of the human brain. Nature. 2011;478:483-9.

[17] Zampieri M, Ciccarone F, Calabrese R, Franceschi C, Burkle A, Caiafa P. Reconfiguration of DNA methylation in aging. Mech Ageing Dev. 2015;151:60-70. 
[18] Gong H, Qian H, Ertl R, Astle CM, Wang GG, Harrison DE, et al. Histone modifications change with age, dietary restriction and rapamycin treatment in mouse brain. Oncotarget. 2015;6:15882-90.

[19] Beveridge NJ, Santarelli DM, Wang X, Tooney PA, Webster MJ, Weickert CS, et al. Maturation of the human dorsolateral prefrontal cortex coincides with a dynamic shift in microRNA expression. Schizophr Bull. 2014;40:399-409.

[20] Danka Mohammed CP, Park JS, Nam HG, Kim K. MicroRNAs in brain aging. Mech Ageing Dev. 2017.

[21] Numata S, Ye T, Hyde TM, Guitart-Navarro X, Tao R, Wininger M, et al. DNA methylation signatures in development and aging of the human prefrontal cortex. Am J Hum Genet. 2012;90:260-72.

[22] Sen P, Shah PP, Nativio R, Berger SL. Epigenetic Mechanisms of Longevity and Aging. Cell. 2016;166:822-39.

[23] Pal S, Tyler JK. Epigenetics and aging. Sci Adv. 2016;2:e1600584.

[24] Tsai PC, Spector TD, Bell JT. Using epigenome-wide association scans of DNA methylation in age-related complex human traits. Epigenomics. 2012;4:511-26.

[25] Christensen BC, Houseman EA, Marsit CJ, Zheng S, Wrensch MR, Wiemels JL, et al. Aging and environmental exposures alter tissue-specific DNA methylation dependent upon CpG island context. PLoS Genet. 2009;5:e1000602.

[26] Day K, Waite LL, Thalacker-Mercer A, West A, Bamman MM, Brooks JD, et al. Differential DNA methylation with age displays both common and dynamic features across human tissues that are influenced by CpG landscape. Genome Biol. 2013;14:R102.

[27] Ihara K, Fuchikami M, Hashizume M, Okada S, Kawai H, Obuchi S, et al. The influence of aging on the methylation status of brain-derived neurotrophic factor gene in blood. Int J Geriatr Psychiatry. 2018;33:1312-8. 
[28] Ratanatharathorn A, Boks MP, Maihofer AX, Aiello AE, Amstadter AB, Ashley - Koch AE, et al. Epigenome - wide association of PTSD from heterogeneous cohorts with a common multi site analysis pipeline. American Journal of Medical Genetics Part B: Neuropsychiatric Genetics. 2017;174:619-30.

[29] Braun PR, Han S, Hing B, Nagahama Y, Gaul LN, Heinzman JT, et al. Genome-wide DNA methylation comparison between live human brain and peripheral tissues within individuals. Translational psychiatry. 2019;9:47.

[30] Aryee MJ, Jaffe AE, Corrada-Bravo H, Ladd-Acosta C, Feinberg AP, Hansen KD, et al. Minfi: a flexible and comprehensive Bioconductor package for the analysis of Infinium DNA methylation microarrays. Bioinformatics. 2014;30:1363-9.

[31] Fortin J-P, Triche Jr TJ, Hansen KD. Preprocessing, normalization and integration of the Illumina HumanMethylationEPIC array with minfi. Bioinformatics. 2016;33:558-60.

[32] Assenov Y, Müller F, Lutsik P, Walter J, Lengauer T, Bock C. Comprehensive analysis of DNA methylation data with RnBeads. Nature methods. 2014;11:1138.

[33] Shinozaki G, Chan AC, Sparr NA, Zarei K, Gaul LN, Heinzman JT, et al. Delirium detection by a novel bispectral electroencephalography device in general hospital. Psychiatry Clin Neurosci. 2018;72:856-63.

[34] Shinozaki G, Bormann NL, Chan AC, Zarei K, Sparr NA, Klisares MJ, et al. Identification of high mortality risk patients and prediction of outcomes in delirium by Bispectral EEG. J Clin Psychiatry. 2019; in press.

[35] Trzepacz PT, Mittal D, Torres R, Kanary K, Norton J, Jimerson N. Validation of the Delirium Rating Scale-revised-98: comparison with the delirium rating scale and the cognitive test for delirium. J Neuropsychiatry Clin Neurosci. 2001;13:229-42.

[36] Schuurmans MJ, Shortridge-Baggett LM, Duursma SA. The Delirium Observation Screening Scale: a screening instrument for delirium. Res Theory Nurs Pract. 2003;17:31-50. 
[37] Morris TJ, Butcher LM, Feber A, Teschendorff AE, Chakravarthy AR, Wojdacz TK, et al. ChAMP: 450k Chip Analysis Methylation Pipeline. Bioinformatics. 2014;30:428-30.

[38] Fortin J-P, Triche T, Hansen K. Preprocessing, normalization and integration of the Illumina HumanMethylationEPIC array. BioRxiv. 2016:065490.

[39] Zhou W, Laird PW, Shen H. Comprehensive characterization, annotation and innovative use of Infinium DNA methylation BeadChip probes. Nucleic Acids Res. 2017;45:e22-e.

[40] Nordlund J, Bäcklin CL, Wahlberg P, Busche S, Berglund EC, Eloranta M-L, et al. Genomewide signatures of differential DNA methylation in pediatric acute lymphoblastic leukemia.

Genome Biol. 2013;14:r105.

[41] Teschendorff AE, Marabita F, Lechner M, Bartlett T, Tegner J, Gomez-Cabrero D, et al. A beta-mixture quantile normalization method for correcting probe design bias in Illumina Infinium 450 k DNA methylation data. Bioinformatics. 2013;29:189-96.

[42] Johnson WE, Li C, Rabinovic A. Adjusting batch effects in microarray expression data using empirical Bayes methods. Biostatistics. 2007;8:118-27.

[43] Leek JT, Johnson WE, Parker HS, Fertig EJ, Jaffe AE, Storey JD, et al. sva: Surrogate variable analysis. R package version. 2019.

[44] R Core Team. R: A language and environment for statistical computing. Vienna, Austria: R Foundation for Statistical Computing; 2019.

[45] Mei X, Tong J. The plasma levels of brain-derived neurotrophic factor are positively associated with emergence agitation in the elderly after gastrointestinal surgery. J Anesth. $2016 ; 30: 811-6$

[46] Wyrobek J, LaFlam A, Max L, Tian J, Neufeld KJ, Kebaish KM, et al. Association of intraoperative changes in brain-derived neurotrophic factor and postoperative delirium in older adults. Br J Anaesth. 2017;119:324-32. 
[47] Grandi C, Tomasi CD, Fernandes K, Stertz L, Kapczinski F, Quevedo J, et al. Brain-derived neurotrophic factor and neuron-specific enolase, but not S100beta, levels are associated to the occurrence of delirium in intensive care unit patients. J Crit Care. 2011;26:133-7.

[48] Brum C, Stertz L, Borba E, Rumi D, Kapczinski F, Camozzato A. Association of serum brain-derived neurotrophic factor (BDNF) and tumor necrosis factor-alpha (TNF-alpha) with diagnosis of delirium in oncology inpatients. Braz J Psychiatry. 2015;37:197-202.

[49] Williams J, Finn K, Melvin V, Meagher D, McCarthy G, Adamis D. The Association of Serum Levels of Brain-Derived Neurotrophic Factor with the Occurrence of and Recovery from Delirium in Older Medical Inpatients. Biomed Res Int. 2017;2017:5271395. 


\section{Figure legend}

Figure 1 Correlation between age and beta value in the top $2 \mathrm{CpGs}$

Abbreviations: BDNF; Brain-derived neurotrophic factor, GDNF; glial cell-derived neurotrophic factor. 
Table 1 : Correlations between age and DNAm levels of neurotrophic genes in blood samples obtained from the GTP cohort

\begin{tabular}{|c|c|c|c|c|}
\hline Gene & $\mathrm{CpG}$ & $\mathrm{t}$ & R square & $p$ \\
\hline GDNF & $\operatorname{cg02328239^{**}}$ & 9.86 & 0.22 & $1.54 \mathrm{E}-20$ \\
\hline$B D N F$ & $\operatorname{cg} 05733135^{* *}$ & 8.18 & 0.17 & $4.49 E-15$ \\
\hline GDNF & $\operatorname{cg} 00049047^{* \star}$ & 7.43 & 0.12 & $7.74 \mathrm{E}-13$ \\
\hline$B D N F$ & $\operatorname{cg} 13974632^{* *}$ & 7.38 & 0.14 & $1.06 \mathrm{E}-12$ \\
\hline$B D N F$ & $\operatorname{cg} 06816235^{* \star}$ & 7.29 & 0.13 & $1.88 \mathrm{E}-12$ \\
\hline$B D N F$ & $\operatorname{cg} 22043168^{* *}$ & 7.07 & 0.12 & $7.92 \mathrm{E}-12$ \\
\hline$N R 4 A 2$ & $\operatorname{cg} 11358945^{* *}$ & 7.04 & 0.14 & $9.50 \mathrm{E}-12$ \\
\hline NPAS4 & $\operatorname{cg} 14699728^{* *}$ & 6.55 & 0.12 & $1.86 \mathrm{E}-10$ \\
\hline GDNF & $\operatorname{cg} 07442479^{* *}$ & 6.55 & 0.12 & $1.88 \mathrm{E}-10$ \\
\hline$B D N F$ & $\operatorname{cg} 23947039^{* *}$ & 6.22 & 0.10 & 1.33E-09 \\
\hline$B D N F$ & $\operatorname{cg} 26949694^{* *}$ & 6.15 & 0.09 & 1.95E-09 \\
\hline$N R 4 A 2$ & $\operatorname{cg} 00194126^{* *}$ & 5.84 & 0.09 & $1.14 \mathrm{E}-08$ \\
\hline$N R 4 A 1$ & $\operatorname{cg} 26446929^{* *}$ & -5.74 & 0.07 & $1.92 \mathrm{E}-08$ \\
\hline$B D N F$ & $\operatorname{cg} 03167496^{* *}$ & 5.71 & 0.10 & $2.25 \mathrm{E}-08$ \\
\hline GDNF & $\operatorname{cg} 26789779^{* *}$ & 5.66 & 0.09 & 2.99E-08 \\
\hline$A R C$ & $\operatorname{cg} 16922810^{* *}$ & -5.60 & 0.09 & $4.11 \mathrm{E}-08$ \\
\hline$B D N F$ & $\operatorname{cg} 01583131^{*}$ & 5.46 & 0.09 & 8.73E-08 \\
\hline$B D N F$ & $\operatorname{cg} 25412831^{*}$ & 5.38 & 0.06 & 1.34E-07 \\
\hline$N R 4 A 2$ & $\operatorname{cg} 14811105^{*}$ & 5.36 & 0.08 & 1.47E-07 \\
\hline GDNF & $\operatorname{cg} 21590264^{*}$ & 5.30 & 0.08 & 1.94E-07 \\
\hline$B D N F$ & $\operatorname{cg} 25962210^{*}$ & 5.18 & 0.09 & 3.58E-07 \\
\hline$N R 4 A 2$ & $\operatorname{cg} 02964555^{*}$ & 5.18 & 0.07 & 3.58E-07 \\
\hline$N R 4 A 2$ & $\operatorname{cg} 21226516^{*}$ & 5.14 & 0.08 & 4.47E-07 \\
\hline$B D N F$ & $\operatorname{cg} 11718030^{*}$ & 4.97 & 0.07 & $1.01 \mathrm{E}-06$ \\
\hline$B D N F$ & $\operatorname{cg} 17413943^{*}$ & 4.90 & 0.05 & $1.41 \mathrm{E}-06$ \\
\hline GDNF & $\operatorname{cg} 25602684^{*}$ & 4.88 & 0.08 & 1.59E-06 \\
\hline GDNF & $\operatorname{cg} 07715201^{*}$ & 4.79 & 0.06 & $2.40 \mathrm{E}-06$ \\
\hline GDNF & $\operatorname{cg} 14492800^{*}$ & 4.77 & 0.08 & 2.62E-06 \\
\hline GDNF & $\operatorname{cg} 08204023^{*}$ & 4.76 & 0.07 & 2.73E-06 \\
\hline NPAS4 & $\operatorname{cg} 04768203^{*}$ & 4.62 & 0.07 & 5.33E-06 \\
\hline GDNF & $\operatorname{cg} 26295057^{*}$ & 4.49 & 0.06 & $9.56 \mathrm{E}-06$ \\
\hline GDNF & $\operatorname{cg} 18182111^{*}$ & 4.42 & 0.04 & $1.31 \mathrm{E}-05$ \\
\hline$B D N F$ & $\operatorname{cg} 04481212^{*}$ & 4.40 & 0.05 & 1.39E-05 \\
\hline$B D N F$ & cg21010859* & 4.39 & 0.05 & $1.51 \mathrm{E}-05$ \\
\hline GDNF & $\operatorname{cg} 21319053^{*}$ & 4.31 & 0.07 & 2.06E-05 \\
\hline$B D N F$ & $\operatorname{cg} 24249411^{*}$ & 4.30 & 0.04 & 2.21E-05 \\
\hline FOS & $\operatorname{cg} 12061886^{*}$ & 4.18 & 0.03 & $3.64 \mathrm{E}-05$ \\
\hline GDNF & $\operatorname{cg} 04209913^{*}$ & 4.18 & 0.04 & 3.66E-05 \\
\hline
\end{tabular}




\begin{tabular}{lllll} 
GDNF & $\mathrm{cg} 18725867^{*}$ & 4.17 & 0.06 & $3.78 \mathrm{E}-05$ \\
GDNF & $\mathrm{cg} 04442426^{*}$ & -4.11 & 0.07 & $4.82 \mathrm{E}-05$ \\
BDNF & $\mathrm{cg} 06684850^{*}$ & 4.09 & 0.05 & $5.29 \mathrm{E}-05$ \\
GDNF & $\mathrm{cg} 05330056^{*}$ & -4.07 & 0.19 & $5.73 \mathrm{E}-05$ \\
BDNF & $\mathrm{cg} 06991510^{*}$ & 4.05 & 0.04 & $6.11 \mathrm{E}-05$ \\
$B D N F$ & $\mathrm{cg} 01225698^{*}$ & 4.04 & 0.03 & $6.57 \mathrm{E}-05$ \\
GDNF & $\mathrm{cg} 14590843^{*}$ & 3.98 & 0.03 & $8.41 \mathrm{E}-05$ \\
$A R C$ & $\mathrm{cg} 19438565^{*}$ & 3.95 & 0.05 & $9.43 \mathrm{E}-05$ \\
$N R 4 A 2$ & $\mathrm{cg} 00426720^{*}$ & 3.93 & 0.04 & $1.03 \mathrm{E}-04$ \\
$N R 4 A 2$ & $\mathrm{cg} 10089963^{*}$ & 3.90 & 0.04 & $1.14 \mathrm{E}-04$ \\
GDNF & $\mathrm{cg} 07423205^{*}$ & 3.85 & 0.04 & $1.40 \mathrm{E}-04$ \\
$B D N F$ & $\mathrm{cg} 25328597^{*}$ & 3.84 & 0.05 & $1.47 \mathrm{E}-04$ \\
$B D N F$ & $\mathrm{cg} 18867480^{*}$ & 3.83 & 0.05 & $1.52 \mathrm{E}-04$ \\
\hline
\end{tabular}

Notes: Blue highlights a positive correlation, and pink highlights a negative correlation.

${ }^{* *}$ Significant after Bonferroni corrected genome-wide significance levels $(p<5 \times E-8)$,

*Significant after correction for multiple testing level $(p<0.05 / 226)$.

Abbreviations: AP-1 Transcription Factor Subunit, ARC; activity regulated cytoskeleton associated protein, BDNF; Brain-derived neurotrophic factor, FOS; Fos Proto-Oncogene, GDNF; glial cell-derived neurotrophic factor, GTP; Grady Trauma Project, NPAS4; neuronal Per-Arnt-Sim domain protein 4, NR4A1; nuclear receptor subfamily 4A1, NR4A2; nuclear receptor subfamily $4 \mathrm{~A} 2$. 
Table 2 : Correlations between age and DNAm levels of neurotrophic genes in brain samples obtained from the NSG cohort

\begin{tabular}{|c|c|c|c|c|}
\hline cgid & Chr & Gene & Rho & $p$ \\
\hline cg08715791* & 11 & NPAS4 & 0.85 & 1.17E-06 \\
\hline $\operatorname{cg} 02328239^{*}$ & 5 & $G D N F$ & 0.85 & $1.26 \mathrm{E}-06$ \\
\hline $\operatorname{cg} 27074041^{*}$ & 2 & $N R 4 A 2$ & 0.82 & 4.87E-06 \\
\hline $\operatorname{cg} 00558219^{*}$ & 2 & $N R 4 A 2$ & 0.75 & 9.09E-05 \\
\hline $\operatorname{cg} 26949694^{*}$ & 11 & $B D N F$ & 0.75 & $9.49 E-05$ \\
\hline $\operatorname{cg} 03230469^{*}$ & 5 & GDNF & 0.73 & 1.67E-04 \\
\hline $\operatorname{cg} 02964555^{\dagger}$ & 2 & $N R 4 A 2$ & 0.70 & 3.85E-04 \\
\hline $\operatorname{cg} 12296752^{\dagger}$ & 11 & $B D N F$ & 0.70 & 4.28E-04 \\
\hline $\operatorname{cg} 04407962^{\dagger}$ & 5 & GDNF & 0.69 & 5.65E-04 \\
\hline $\operatorname{cg} 20570611^{\dagger}$ & 2 & $N R 4 A 2$ & 0.68 & 6.67E-04 \\
\hline $\operatorname{cg} 04768203^{\dagger}$ & 11 & NPAS4 & 0.67 & 9.36E-04 \\
\hline $\operatorname{cg} 12930882^{\dagger}$ & 5 & GDNF & 0.64 & 0.002 \\
\hline $\operatorname{cg} 20108357^{\dagger}$ & 11 & $B D N F$ & 0.63 & 0.002 \\
\hline $\operatorname{cg} 04209913^{\dagger}$ & 5 & GDNF & 0.62 & 0.003 \\
\hline $\operatorname{cg} 14811105^{\dagger}$ & 2 & $N R 4 A 2$ & 0.62 & 0.003 \\
\hline $\operatorname{cg} 07238832^{\dagger}$ & 11 & $B D N F$ & 0.61 & 0.003 \\
\hline $\operatorname{cg} 06684850^{\dagger}$ & 11 & $B D N F$ & 0.60 & 0.004 \\
\hline $\operatorname{cg} 11358945^{\dagger}$ & 2 & $N R 4 A 2$ & 0.60 & 0.004 \\
\hline $\operatorname{cg} 21286419^{\dagger}$ & 5 & GDNF & 0.60 & 0.004 \\
\hline $\operatorname{cg} 16058600^{\dagger}$ & 2 & $N R 4 A 2$ & 0.58 & 0.006 \\
\hline $\operatorname{cg} 11209121^{\dagger}$ & 2 & $N R 4 A 2$ & 0.58 & 0.006 \\
\hline $\operatorname{cg} 01107142^{\dagger}$ & 5 & GDNF & 0.57 & 0.007 \\
\hline $\operatorname{cg} 26559974^{\dagger}$ & 5 & $G D N F$ & 0.57 & 0.007 \\
\hline $\operatorname{cg} 01123282^{\dagger}$ & 2 & $N R 4 A 2$ & -0.57 & 0.007 \\
\hline $\operatorname{cg} 04106006^{\dagger}$ & 11 & $B D N F$ & 0.57 & 0.007 \\
\hline $\operatorname{cg} 00194126^{\dagger}$ & 2 & $N R 4 A 2$ & 0.56 & 0.008 \\
\hline $\operatorname{cg} 17654050^{\dagger}$ & 2 & $N R 4 A 2$ & 0.56 & 0.008 \\
\hline $\operatorname{cg} 15368455^{\dagger}$ & 5 & GDNF & 0.56 & 0.008 \\
\hline $\operatorname{cg} 14291693^{\dagger}$ & 11 & $B D N F$ & 0.56 & 0.009 \\
\hline $\operatorname{cg} 14590843^{\dagger}$ & 5 & GDNF & 0.56 & 0.009 \\
\hline $\operatorname{cg} 08760147^{\dagger}$ & 11 & $B D N F$ & 0.55 & 0.010 \\
\hline $\operatorname{cg} 00761985^{\dagger}$ & 5 & $G D N F$ & 0.55 & 0.010 \\
\hline $\operatorname{cg} 14617996^{\dagger}$ & 2 & $N R 4 A 2$ & 0.54 & 0.011 \\
\hline $\operatorname{cg} 18595174^{\dagger}$ & 11 & $B D N F$ & 0.54 & 0.012 \\
\hline $\operatorname{cg} 05189570^{\dagger}$ & 11 & $B D N F$ & 0.53 & 0.013 \\
\hline $\operatorname{cg} 15710245^{\dagger}$ & 11 & $B D N F$ & -0.53 & 0.013 \\
\hline $\operatorname{cg} 13500877^{\dagger}$ & 2 & $N R 4 A 2$ & 0.53 & 0.014 \\
\hline $\operatorname{cg} 01583131^{\dagger}$ & 11 & $B D N F$ & 0.53 & 0.014 \\
\hline
\end{tabular}




\begin{tabular}{|c|c|c|c|c|}
\hline $\operatorname{cg} 00240195^{\dagger}$ & 2 & $N R 4 A 2$ & 0.52 & 0.015 \\
\hline $\operatorname{cg} 25928860^{\dagger}$ & 11 & $B D N F$ & 0.52 & 0.016 \\
\hline $\operatorname{cg} 10558494^{\dagger}$ & 11 & $B D N F$ & -0.52 & 0.016 \\
\hline $\operatorname{cg} 03167496^{\dagger}$ & 11 & $B D N F$ & 0.51 & 0.018 \\
\hline $\operatorname{cg} 23097534^{\dagger}$ & 5 & GDNF & 0.51 & 0.018 \\
\hline $\operatorname{cg} 06816235^{\dagger}$ & 11 & $B D N F$ & 0.51 & 0.019 \\
\hline $\operatorname{cg} 06101180^{\dagger}$ & 2 & $N R 4 A 2$ & 0.51 & 0.019 \\
\hline $\operatorname{cg} 06260077^{\dagger}$ & 11 & $B D N F$ & 0.50 & 0.021 \\
\hline $\operatorname{cg} 16246410^{\dagger}$ & 2 & $N R 4 A 2$ & -0.50 & 0.021 \\
\hline $\operatorname{cg} 17413943^{\dagger}$ & 11 & $B D N F$ & 0.49 & 0.024 \\
\hline $\operatorname{cg} 11932911^{\dagger}$ & 2 & $N R 4 A 2$ & 0.49 & 0.024 \\
\hline $\operatorname{cg} 11399967^{\dagger}$ & 2 & $N R 4 A 2$ & 0.49 & 0.024 \\
\hline $\operatorname{cg} 09606766^{\dagger}$ & 11 & $B D N F$ & -0.49 & 0.025 \\
\hline $\operatorname{cg} 10089963^{\dagger}$ & 2 & $N R 4 A 2$ & 0.49 & 0.025 \\
\hline $\operatorname{cg} 21226516^{\dagger}$ & 2 & $N R 4 A 2$ & 0.48 & 0.027 \\
\hline $\operatorname{cg} 02331025^{\dagger}$ & 5 & GDNF & 0.48 & 0.027 \\
\hline $\operatorname{cg} 23400942^{\dagger}$ & 5 & $G D N F$ & 0.47 & 0.030 \\
\hline $\operatorname{cg} 19717018^{\dagger}$ & 5 & $G D N F$ & 0.47 & 0.031 \\
\hline $\operatorname{cg} 10635145^{\dagger}$ & 11 & $B D N F$ & 0.46 & 0.035 \\
\hline $\operatorname{cg} 15699971^{\dagger}$ & 2 & $N R 4 A 2$ & -0.46 & 0.036 \\
\hline $\operatorname{cg} 07159484^{\dagger}$ & 11 & $B D N F$ & -0.44 & 0.044 \\
\hline $\operatorname{cg} 03339537^{\dagger}$ & 2 & $N R 4 A 2$ & 0.44 & 0.045 \\
\hline $\operatorname{cg} 18941818^{\dagger}$ & 2 & $N R 4 A 2$ & 0.44 & 0.048 \\
\hline $\operatorname{cg} 01546433^{\dagger}$ & 11 & $B D N F$ & 0.43 & 0.049 \\
\hline
\end{tabular}

Notes: Blue highlights a positive correlation, and pink highlights a negative correlation.

*Significant after correction for multiple testing level $(p<0.05 / 201),{ }^{\dagger}$ nominally significant $(p<$ 0.05).

Abbreviations: BDNF; Brain-derived neurotrophic factor, GDNF; glial cell-derived neurotrophic factor, NPAS4; neuronal Per-Arnt-Sim domain protein 4, NR4A2; nuclear receptor subfamily 4A2, NSG; neurosurgery. 
Table 3 : Correlation of age and blood DNAm at 83 CpGs in the BDNF gene compared between delirium cases vs non-delirium controls in the EOD cohort

\begin{tabular}{|c|c|c|c|c|c|c|}
\hline \multirow{2}{*}{ Gene } & \multicolumn{3}{|c|}{ Delirium Cases $(\mathrm{N}=43)$} & \multicolumn{3}{|c|}{ Non Delirium Controls $(\mathrm{N}=44)$} \\
\hline & CpG & $r$ & p-value & $\mathrm{CpG}$ & $r$ & $\mathrm{p}$-value \\
\hline \multirow{35}{*}{$B D N F$} & $\operatorname{cg} 06816235^{*}$ & 0.52 & $3.68 E-04$ & $\operatorname{cg} 20340655^{\dagger}$ & 0.38 & 0.010 \\
\hline & $\operatorname{cg} 05733135^{\dagger}$ & 0.43 & 0.004 & $\operatorname{cg} 26949694^{\dagger}$ & 0.30 & 0.047 \\
\hline & $\operatorname{cg} 13974632^{\dagger}$ & 0.39 & 0.010 & $\operatorname{cg} 06046431^{\dagger}$ & 0.30 & 0.048 \\
\hline & $\operatorname{cg} 25328597^{\dagger}$ & 0.37 & 0.015 & $\operatorname{cg} 04106006$ & 0.26 & 0.088 \\
\hline & $\operatorname{cg} 10022526^{\dagger}$ & 0.36 & 0.017 & $\operatorname{cg} 06816235$ & 0.26 & 0.091 \\
\hline & cg09505801 & 0.30 & 0.052 & $\operatorname{cg} 18117895$ & 0.25 & 0.098 \\
\hline & $\operatorname{cg} 11718030$ & 0.30 & 0.053 & $\operatorname{cg} 13974632$ & 0.22 & 0.143 \\
\hline & $\operatorname{cg} 01642653$ & 0.29 & 0.060 & $\operatorname{cg} 06684850$ & 0.22 & 0.155 \\
\hline & $\operatorname{cg} 27351358$ & 0.26 & 0.087 & $\operatorname{cg} 15710245$ & 0.21 & 0.173 \\
\hline & cg04106006 & 0.26 & 0.092 & cg25457956 & 0.20 & 0.186 \\
\hline & cg07159484 & 0.25 & 0.100 & cg09505801 & 0.20 & 0.193 \\
\hline & cg01583131 & 0.25 & 0.103 & cg10022526 & 0.20 & 0.204 \\
\hline & $\operatorname{cg} 17882499$ & 0.24 & 0.124 & cg23947039 & 0.19 & 0.207 \\
\hline & cg10558494 & 0.23 & 0.134 & $\operatorname{cg} 17413943$ & 0.19 & 0.221 \\
\hline & $\operatorname{cg} 15710245$ & 0.23 & 0.145 & cg22043168 & 0.17 & 0.258 \\
\hline & cg23619332 & 0.22 & 0.161 & cg05218375 & 0.17 & 0.264 \\
\hline & cg25156688 & 0.21 & 0.177 & cg25928860 & 0.16 & 0.304 \\
\hline & cg06991510 & 0.21 & 0.183 & cg01225698 & 0.15 & 0.334 \\
\hline & cg08362738 & 0.20 & 0.193 & cg21010859 & 0.15 & 0.345 \\
\hline & $\operatorname{cg} 17413943$ & 0.19 & 0.215 & cg08362738 & 0.13 & 0.414 \\
\hline & cg09492354 & 0.19 & 0.217 & cg05733135 & 0.12 & 0.438 \\
\hline & cg25457956 & 0.18 & 0.244 & cg06979684 & 0.12 & 0.454 \\
\hline & cg04481212 & 0.17 & 0.280 & cg01583131 & 0.11 & 0.480 \\
\hline & $\operatorname{cg} 15313332$ & 0.17 & 0.287 & cg05189570 & 0.10 & 0.503 \\
\hline & cg02613510 & 0.16 & 0.298 & $\operatorname{cg} 11806762$ & 0.09 & 0.570 \\
\hline & cg22128379 & 0.16 & 0.307 & cg07159484 & 0.09 & 0.575 \\
\hline & cg11865360 & 0.16 & 0.315 & cg24650785 & 0.07 & 0.645 \\
\hline & cg03984780 & 0.15 & 0.331 & cg20954537 & 0.07 & 0.648 \\
\hline & cg27193031 & 0.15 & 0.337 & cg01546433 & 0.07 & 0.652 \\
\hline & $\operatorname{cg} 10635145$ & 0.15 & 0.341 & $\operatorname{cg} 15914769$ & 0.07 & 0.655 \\
\hline & cg26949694 & 0.15 & 0.342 & cg08760147 & 0.06 & 0.676 \\
\hline & cg06979684 & 0.15 & 0.349 & $\operatorname{cg} 12021170$ & 0.06 & 0.682 \\
\hline & $\operatorname{cg} 11806762$ & 0.14 & 0.361 & cg22288103 & 0.06 & 0.682 \\
\hline & cg06025631 & 0.14 & 0.369 & cg03984780 & 0.06 & 0.719 \\
\hline & cg01225698 & 0.14 & 0.387 & cg06025631 & 0.05 & 0.731 \\
\hline
\end{tabular}




\begin{tabular}{|c|c|c|c|c|c|}
\hline cg07238832 & 0.14 & 0.388 & cg27351358 & 0.05 & 0.734 \\
\hline cg24650785 & 0.12 & 0.458 & $\operatorname{cg} 01642653$ & 0.05 & 0.737 \\
\hline cg22043168 & 0.12 & 0.458 & cg03167496 & 0.05 & 0.746 \\
\hline $\operatorname{cg} 16257091$ & 0.12 & 0.459 & $\operatorname{cg} 25156688$ & 0.04 & 0.798 \\
\hline cg15462887 & 0.12 & 0.462 & $\operatorname{cg} 11718030$ & 0.04 & 0.819 \\
\hline cg06684850 & 0.11 & 0.468 & cg07704699 & 0.03 & 0.856 \\
\hline cg23947039 & 0.11 & 0.471 & cg20108357 & 0.03 & 0.860 \\
\hline cg05218375 & 0.11 & 0.488 & $\operatorname{cg} 24249411$ & 0.03 & 0.868 \\
\hline cg07704699 & 0.11 & 0.499 & $\operatorname{cg} 01636003$ & 0.02 & 0.891 \\
\hline cg06046431 & 0.10 & 0.510 & $\operatorname{cg} 15462887$ & 0.02 & 0.923 \\
\hline cg24065044 & 0.09 & 0.548 & $\operatorname{cg} 05847680$ & 0.01 & 0.924 \\
\hline $\operatorname{cg} 21010859$ & 0.09 & 0.550 & $\operatorname{cg} 03747251$ & 0.00 & 0.999 \\
\hline cg09606766 & 0.08 & 0.599 & cg00298481 & 0.00 & 0.990 \\
\hline $\operatorname{cg} 11241206$ & 0.08 & 0.615 & $\operatorname{cg} 11865360$ & -0.01 & 0.958 \\
\hline cg12067298 & 0.08 & 0.623 & cg10558494 & -0.01 & 0.951 \\
\hline cg20954537 & 0.07 & 0.637 & cg02386994 & -0.02 & 0.917 \\
\hline cg04672351 & 0.06 & 0.684 & $\operatorname{cg} 12067298$ & -0.02 & 0.908 \\
\hline cg03747251 & 0.06 & 0.692 & cg02527472 & -0.03 & 0.867 \\
\hline cg03167496 & 0.05 & 0.731 & $\operatorname{cg} 04481212$ & -0.03 & 0.867 \\
\hline $\operatorname{cg} 12448003$ & 0.05 & 0.749 & $\operatorname{cg} 11241206$ & -0.03 & 0.850 \\
\hline cg05818894 & 0.04 & 0.801 & $\operatorname{cg} 22128379$ & -0.03 & 0.832 \\
\hline cg22288103 & 0.03 & 0.860 & $\operatorname{cg} 14291693$ & -0.03 & 0.828 \\
\hline cg08388004 & 0.02 & 0.906 & $\operatorname{cg} 17882499$ & -0.04 & 0.808 \\
\hline cg08760147 & 0.01 & 0.938 & $\operatorname{cg} 15313332$ & -0.05 & 0.771 \\
\hline cg20340655 & -0.01 & 0.940 & $\operatorname{cg} 26057780$ & -0.05 & 0.739 \\
\hline cg02527472 & -0.02 & 0.902 & $\operatorname{cg} 26840770$ & -0.05 & 0.732 \\
\hline cg24249411 & -0.02 & 0.896 & $\operatorname{cg} 25328597$ & -0.06 & 0.709 \\
\hline cg02386994 & -0.03 & 0.844 & $\operatorname{cg} 06991510$ & -0.06 & 0.676 \\
\hline cg18117895 & -0.04 & 0.817 & $\operatorname{cg} 24065044$ & -0.07 & 0.637 \\
\hline cg05847680 & -0.04 & 0.807 & $\operatorname{cg} 18354203$ & -0.07 & 0.633 \\
\hline cg26057780 & -0.04 & 0.777 & cg04672351 & -0.08 & 0.621 \\
\hline $\operatorname{cg} 12021170$ & -0.06 & 0.720 & $\operatorname{cg} 09606766$ & -0.08 & 0.595 \\
\hline cg15914769 & -0.07 & 0.673 & cg07238832 & -0.10 & 0.529 \\
\hline $\operatorname{cg} 18354203$ & -0.08 & 0.627 & cg06260077 & -0.10 & 0.514 \\
\hline cg15014679 & -0.08 & 0.597 & cg05818894 & -0.11 & 0.494 \\
\hline cg26840770 & -0.12 & 0.429 & $\operatorname{cg} 12448003$ & -0.11 & 0.481 \\
\hline cg00298481 & -0.13 & 0.412 & $\operatorname{cg} 10635145$ & -0.13 & 0.409 \\
\hline cg01636003 & -0.14 & 0.385 & $\operatorname{cg} 16257091$ & -0.14 & 0.374 \\
\hline cg05189570 & -0.15 & 0.336 & cg09492354 & -0.15 & 0.331 \\
\hline cg06260077 & -0.15 & 0.336 & $\operatorname{cg} 23143371$ & -0.15 & 0.317 \\
\hline cg23143371 & -0.17 & 0.275 & $\operatorname{cg} 23619332$ & -0.20 & 0.200 \\
\hline
\end{tabular}




\begin{tabular}{|l|l|l|l|l|l|l|}
$\operatorname{cg} 23426002$ & -0.18 & 0.243 & $\operatorname{cg} 18595174$ & -0.20 & 0.189 \\
$\operatorname{cg} 20108357$ & -0.21 & 0.178 & $\operatorname{cg} 23426002$ & -0.21 & 0.181 \\
$\operatorname{cg} 18595174$ & -0.22 & 0.162 & $\operatorname{cg} 27193031$ & -0.23 & 0.128 \\
$\operatorname{cg} 14291693$ & -0.23 & 0.137 & $\operatorname{cg} 02613510$ & -0.26 & 0.084 \\
$\operatorname{cg} 01546433$ & -0.25 & 0.105 & $\operatorname{cg} 15688670$ & -0.30 & 0.046 \\
$\operatorname{cg} 15688670$ & -0.26 & 0.092 & $\operatorname{cg} 08388004$ & -0.31 & 0.041 \\
cg25928860 & -0.30 & 0.047 & $\operatorname{cg} 15014679$ & -0.34 & 0.023 \\
\hline
\end{tabular}

Notes: Blue highlights a positive correlation, and pink highlights a negative correlation.

*Significant after correction for multiple testing level $(p<0.05 / 192),{ }^{\dagger}$ nominally significant $(p<$ 0.05).

Abbreviations: BDNF; Brain-derived neurotrophic factor, DNAm; DNA methylation, EOD;

Epigenetics of Delirium. 

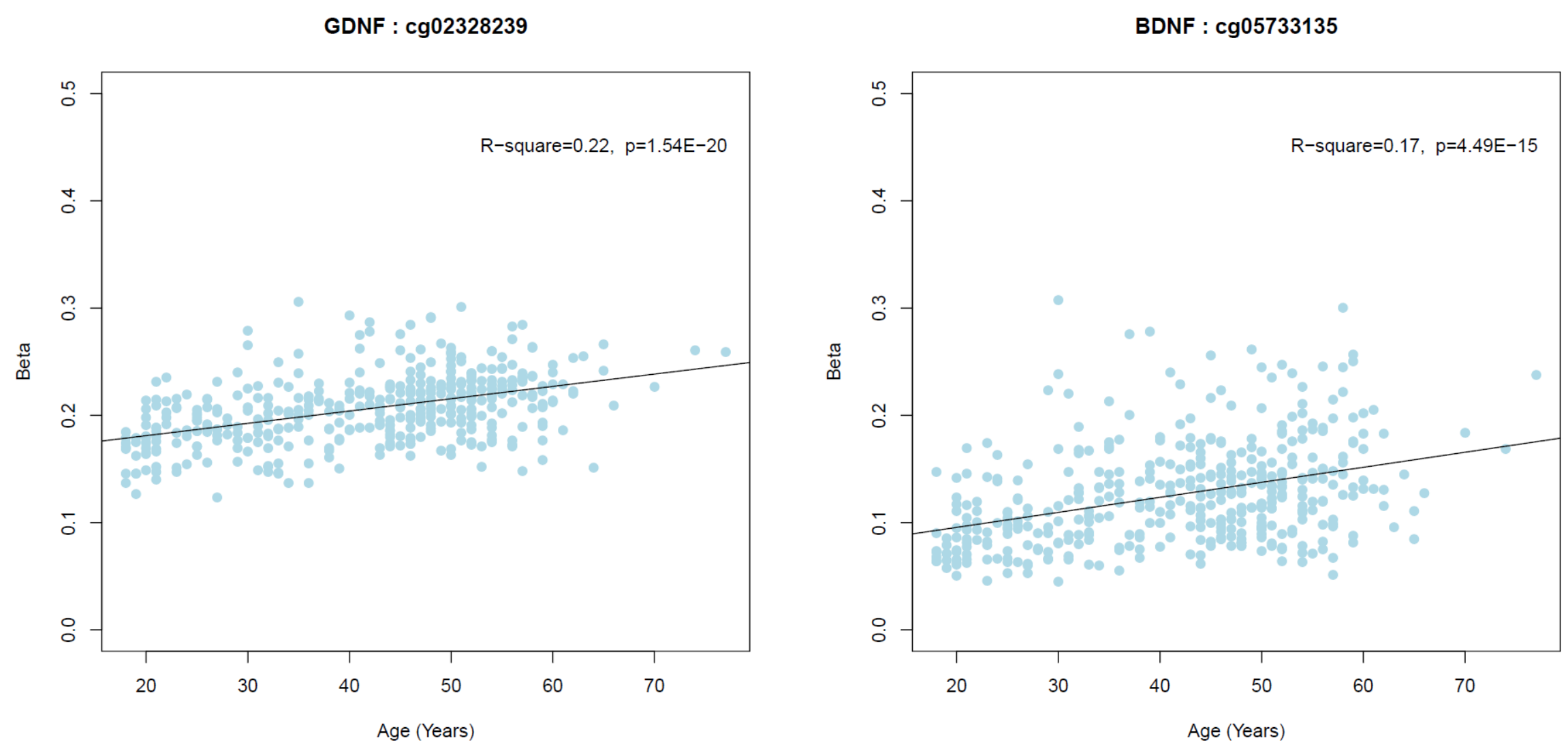